\title{
Prevention, detection, and response to anthrax outbreak in Northern Tanzania using one health approach: A case study of Selela ward in Monduli district
}

\author{
Elibariki R. Mwakapeje ${ }^{1,2,3}$, Justine A. Assenga ${ }^{4}$, John S. Kunda ${ }^{4}$, Ernest E. Mjingo ${ }^{5}$, Zachariah E. Makondo ${ }^{6}$, \\ Hezron E. Nonga ${ }^{2}$, Robinson H. Mdegela ${ }^{2}$ and Eystein Skjerve ${ }^{3}$
}

\begin{abstract}
1. Department of Preventive Health Services, Ministry of Health, Community Development, Gender, Elderly and Children, Dar es Salaam, Tanzania; 2. Department of Veterinary Medicine and Public Health, Sokoine University of Agriculture, Morogoro, Tanzania; 3. Department of Food Safety and Infection Biology, Norwegian University of Life Sciences, Oslo, Norway; 4. National One Health Coordination Unit, Department of Disaster Management, The Prime Minister's Office, Dar es Salaam Tanzania; 5. Tanzania Wildlife Research Institute and the Nelson Mandela African Institute of Science and Technology, Arusha, Tanzania; 6. Tanzania Veterinary Laboratory Agency, Ministry of Agriculture, Livestock and Fisheries, Dar es Salaam, Tanzania.
\end{abstract}

Corresponding author: Elibariki R. Mwakapeje, e-mail: elibariki.reuben.mwakapeje@nmbu.no

Co-authors: JAA: assengakanda@yahoo.com,JSK: jkundas@yahoo.com, EEM: eblate.ernest@gmail.com, ZEM: zmakondo@gmail.com, HEN: nongahezron@yahoo.co.uk,RHM: rmdegela2012@gmail.com,

ES: eystein.skjerve@nmbu.no

Received: 29-07-2017, Accepted: 03-10-2017, Published online: 04-11-2017

doi: 10.14202/IJOH.2017.66-76 How to cite this article: Mwakapeje ER, Assenga JA, Kunda JS, Mjingo EE, Makondo ZE, Nonga HE, Mdegela RH, Skjerve E. Prevention, detection, and response to anthrax outbreak in Northern Tanzania using one health approach: A case study of Selela ward in Monduli district. Int J One Health 2017;3:66-76.

\begin{abstract}
Background: Anthrax is an infectious fatal zoonotic disease caused by Bacillus anthracis. Anthrax outbreak was confirmed in samples of wild animals following rumors of the outbreak in wild animals, livestock, and humans in Selela ward, Monduli district of Northern Tanzania. Therefore, a multi-sectoral team was deployed for outbreak response in the affected areas.

Objectives: The aim of the response was to manage the outbreak in a One Health approach and specifically: (i) To determine the magnitude of anthrax outbreak in humans, livestock, and wild animals in Selela ward, (ii) to assess the outbreak local response capacity, (iii) to establish mechanisms for safe disposal of animal carcasses in the affected areas, and (iv) to mount effective control and preventive strategies using One Health approach in the affected areas.

Materials and Methods: This was a cross-sectional field survey using: (i) Active searching of suspected human cases at health facilities and community level, (ii) physical counting and disposal of wild animal carcasses in the affected area, (iii) collection of specimens from suspected human cases and animal carcasses for laboratory analysis, and (iv) meetings with local animal and human health staff, political, and traditional leaders at local levels. We analyzed data by STATA software, and a map was created using Quantum GIS software.

Results: A total of 21 humans were suspected, and most of them (62\%) being from Selela ward. The outbreak caused deaths of 10 cattle, 26 goats, and three sheep, and 131 wild animal carcasses were discarded the majority of them being wildebeest (83\%). Based on laboratory results, three blood smears tested positive for anthrax using Giemsa staining while two wildebeest samples tested positive and five human blood samples tested negative for anthrax using quantitative polymerase chain reaction techniques. Clinical forms of anthrax were also observed in humans and livestock which suggest that wild animals may contribute as reservoir of anthrax which can easily be transmitted to humans and livestock.

Conclusion: The rapid outbreak response by multi-sectoral teams using a One Health approach managed to contain the outbreak. The teams were composed of animal and human health experts from national to village levels to control the outbreak. The study testifies the importance of multi-sectoral collaboration using One Health approach in outbreak preparedness and response.
\end{abstract}

Keywords: anthrax outbreak, human - livestock and wild animal's interface, response, Tanzania.

\section{Introduction}

Anthrax is a zoonotic infectious disease caused by a Gram-positive, rod-shaped spore-forming bacterium called Bacillus anthracis [1]. The disease affects

Copyright: Mwakapeje, et al. This article is an open access article distributed under the terms of the Creative Commons Attribution 4.0 International License (http://creativecommons.org/licenses/ by/4.0/), which permits unrestricted use, distribution, and reproduction in any medium, provided you give appropriate credit to the original author(s) and the source, provide a link to the Creative Commons license, and indicate if changes were made. The Creative Commons Public Domain Dedication waiver (http:// creativecommons.org/ publicdomain/zero/1.0/) applies to the data made available in this article, unless otherwise stated. mainly herbivores, causing fatalities in the majority of infected cases [2]. Infection in human occurs when $B$. anthracis penetrates through skin abrasions or mucous membranes when there is a contact with infected anthrax carcasses or animal products, inhalation of spores, or consumption of undercooked infected carcass [3]. Three types of anthrax occur in humans depending on the route of transmission; these include cutaneous, gastrointestinal, and inhalational forms [1]. The inhalational form is acquired through inhaling anthrax spores, while the gastrointestinal form is more severe, acquired through consumption of raw or inadequately cooked products from infected 
animals. It may also represent a significant burden which is both poorly reported and misdiagnosed [4]. The soil is the primary reservoir of $B$. anthracis [5].

Herbivores are infected when they graze in an area where the soil or water sources have been contaminated by B. anthracis spores [3]. Anthrax outbreaks are often associated with low-lying areas with soil that has high moisture, calcium, prolonged periods of hot and dry weather, organic content, and alkaline $\mathrm{pH}$ [1]. Insects have been implicated in the spread of anthrax outbreaks, including both transmissions of a disease by biting or carrion flies spreading the spores onto vegetation which is then consumed by browsing animals $[3,6,7]$. Spores can persist in the soil under extreme weather and environmental conditions for an extended period [8].

The burden and economic impacts of anthrax in domestic animals are not fully understood [9]. However, epizootics occur each year, resulting in massive deaths of animals, and spill over to humans often occurs by direct contact with infected animals or their products such as meat, hides, bones, and other materials. Estimates show that a total of 2000-20,000 human anthrax cases are being reported annually worldwide [2]. Endemic hotspot areas for anthrax outbreaks exist in most parts of the world including Africa, Asia, United States, and Australia [10]. China, for instance, has experienced three large-scale anthrax outbreaks with 112,000 human cases from 1956 to 1997 [11]. Another outbreak affected 124 animals of different species: 81 cattle, 15 sheep, 9 goats, and 11 horses in Basilicata region and 8 deer of Pollino National Park in Italy $[12,13]$. In Bangladesh, a multi-sectoral team investigated 14 anthrax outbreaks and identified a total of 140 animal carcasses and 273 human cases of cutaneous anthrax in the recent years [14,15]. Other studies have reported a total of 52 cases of cutaneous anthrax, and 24 cases of oropharyngeal anthrax in humans after anthrax was found in water buffaloes in March-April 1982 in Chiang Mai, Northern Thailand [4].

Anthrax is epizootic throughout Africa, leading to considerable economic losses of livestock and wild animals, costs for laboratory testing and carcass disposal (burning or burial), and severe, sometimes fatal infection in humans. In Zimbabwe, during 19952005 , a total of 282 outbreaks and 2978 animal cases (livestock and wildlife) were reported [16]. Anthrax is one of the major threats to animals and humans in the Western part of Zambia, in 2010, it affected 45 cattle and three humans [17]. A total of 306 hippopotami died from a confirmed anthrax outbreak in the Queen Elizabeth National Part of Uganda in 2004. It was representing $11.63 \%$ of the total hippo population in the park [18].

In Tanzania, studies show that anthrax outbreaks are frequently occurring in the country, for instance, in $1998,2003,2006$, and 2009, many species were affected including livestock, humans, and wildlife.
Overall, seropositivity was found higher in carnivores from Serengeti National Park and Ngorongoro Crater by $90 \%$ and $57 \%$, respectively, and significantly lower in herbivores by $46 \%$ and $14 \%$, respectively [19]. In humans, hospital records show that 7,538 cases were suspected for anthrax and 8 cases were confirmed for gastrointestinal form with four deaths (case fatality rate 50\%) during 1999-2006 [5]. Recent reports indicate the occurrence of the anthrax outbreak in Rombo district of Northern Tanzania affecting four people leaving one died after acquiring infection from infected cattle in 2016 [20]. However, the available statistics on the magnitude of anthrax in the country might not be exhaustive, due to poor surveillance systems and diagnostic capacities in both human and animal sectors [21].

Anthrax has become a disease of public health and economic importance because of its increased incidences both in humans and animals and also impairing the livelihood of human beings [22]. It might be exacerbated by the increased proximity to wildlife protected areas, human behavior of consuming raw or undercooked carcasses from sick or dead animals, poor farming practices, and mismanaged cross-border movement of animals (livestock and wildlife) from one area to another as far as neighboring countries are concerned [23-25]. Control measures against anthrax outbreaks addressed in Tanzania include targeted routine livestock vaccination, intensified disease surveillance, multi-sectoral response to outbreaks, and health education to communities at risk [23].

The Government of Tanzania through the Prime Minister's Office has developed a National One Health Strategic Plan for the period 2015-2020. The plan has a clear focus on ensuring the implementation of human and animal health services by engaging various sectors to enhanced collaboration among livestock, wildlife, and human health sectors for prevention and control of zoonotic diseases [26]. These teams are currently centered at the national level, and plans are underway to replicate these teams at region, district, ward, and village levels countrywide.

Early November 2016 rumors circulated about massive deaths of animals and existence of suspect human anthrax cases in Selela ward, Monduli district of Northern Tanzania. The initial report showed that 80 wildebeests, 6 impala, and 28 cattle deaths were reported to the District Executive Officer. After preliminary laboratory investigation results, the District Commissioner announced the existence of anthrax outbreak in that area. The Monduli District Medical Officer (DMO) communicated the outbreak information to the Ministry of Health, Community Development, Gender, Elderly, and Children that there were two suspected cases of human anthrax in Mto wa Mbu and Mbaash Dispensaries. The human suspect cases were also reported through the electronic integrated diseases surveillance and response (e-IDSR) system. 
The One Health Coordination Unit, under the Disaster Management Department of the Prime Minister's Office, formulated a multi-sectoral response team of experts from human, livestock, and wildlife sectors to the region, district, and the affected villages. This team constituted experts from the Prime Minister's Office (National One Health Coordination Unit), Ministry of Health, Community Development, Gender, Elderly and Children, Regional Medical Officer's office, Tanzania Wildlife Research Institute (TAWIRI), DMO, District Veterinary Officer (DVO), and the District Game Officer. The main aim of the response was (i) to create and strengthen regional, district, and village multi-sectoral teams to manage the outbreak, (ii) to determine the magnitude of anthrax outbreak in humans, livestock, and wild animals, and (iii) to sensitize the community on their involvement in the disease prevention and control, the team also intended to address challenges facing the community on prevention and control of anthrax, and other epidemics.

\section{Materials and Methods \\ Ethical approval}

The study was approved by the National Health Research Review Committee of the National Institute for Medical Research (NIMR), Tanzania (Reference Number. NIMR/HQ/R.8aVol.IX/2286). Verbal informed consent was sought from all human subjects before being involved with study activities. For underage, parents or guardians consented on their behalf. We observed confidentiality at all times during the study, names or personal identifications were not used nor disclosing personal details including laboratory results without prior permission. Moreover, during human blood sampling, pre-counseling was conducted, and all measures were taken to make sure minimal pain is inflicted to study participants. All confirmed cases were treated according to Tanzania Standard Treatment Guidelines for anthrax.

\section{Study design}

This study was designed as a cross-sectional survey employing both quantitative and qualitative methods in data collection.

\section{Study area}

We conducted this study in Monduli district of the Northern part of Tanzania. Monduli district is one of the districts of Arusha region with the majority of people keeping animals. The district forms a part of the Great East African Rift Valley, characterized by some isolated mountains in the flat and rolling plains. Steep escarpments extend along the Western border of the district with the highest point being $2900 \mathrm{~m}$ above sea level and the lowest near Lake Natron, $600 \mathrm{~m}$ above sea level. The district is located in the middle of one of Tanzania's most important world renowned wildlife and nature-based tourism regions. About 95\% of the land area of the district is made up of game controlled areas where wildlife migrates to the wet season from the surrounding National Parks.

Administratively, the district is divided into three divisions (Manyara, Makuyuni, and Kisongo), 15 wards, and 48 villages. The district is part of the northern tourist circuit, surrounded by some of the world's most famous natural attractions. To reach those attractions, tourists must travel through Monduli district. They include the following, to the West of Monduli district (Serengeti National Park - with vast herds of wildlife, including the wildebeest migration, Tarangire National Park - with a high concentration of different species of animals, particularly elephants in this low intervention National Park. The park is well known for its tree-climbing pythons, Lake Manyara National Park with tree-climbing lions, groundwater forests, hot springs, and Ngorongoro crater and conservation area). The main economic activities of Monduli district are livestock keeping, agriculture production, and tourism. More than $90 \%$ of the district population is engaged in livestock keeping and agricultural activities. The major ethnic group of this district is the Maasai (whose main activity is livestock keeping), and they constitute about $40 \%$ of the entire population. The second ethnic group is the Waarusha who constitute about $20 \%$ of the population, and they practice livestock keeping and agricultural activities. The rest of the population who are not indigenous constitutes $40 \%$, and their main activities are farming and trading [27].

\section{Response to anthrax outbreak and field survey}

A suspect case of human anthrax was defined as any person with an acute onset of illness characterized by several clinical forms including (i) localized form - skin lesions and (ii) systemic forms - gastrointestinal, pulmonary, and meningeal. A confirmed case was any suspect case with the above symptoms and laboratory confirmation of $B$. anthracis from a clinical specimen $[28,29]$. A suspected animal case of anthrax occurs when the animal suffers a sudden death accompanied with one of the following signs: Lack of rigor mortis (legs not stiff), blood oozing from the nose, mouth, and other natural body openings, subcutaneous swellings, rapid bloating, and dark non-clotting blood [30]. Additional symptoms in cattle, horses, sheep, and some wild herbivores include fever, dyspnea, agitation, and convulsions followed by death [31].

During field surveys, the following methods were used to find cases and collect data (i) active searching of suspect human anthrax case at health facilities and community level, (ii) species identification and physical counting of carcasses of wild animals in the affected areas, (iii) collection of specimens from suspected human cases and carcasses of wild animals for laboratory analysis, (iv) burying and burning of carcasses of wild animals followed by disinfection of the burial area using lime 
or $10 \%$ formalin, and (vi) meetings with local political and traditional leaders at the district headquarters and Selela ward, and also visiting households with reported anthrax human cases to observe the herd status and search for active human cases at community level. During the visits, sensitization on the mode of transmission, prevention, and control of anthrax was done. At the end of the survey, carcasses of dead wild animals were either buried in a pit of $6 \mathrm{ft}$ and disinfected with $10 \%$ formalin or incinerated. The field work for this outbreak response was done during the $2^{\text {nd }}$ and $3^{\text {rd }}$ weeks of November 2016.

\section{Laboratory diagnosis}

The DVO initially collected specimen from three wildebeests which included the impression blood smears. The specimens were sent to the Tanzania Veterinary Laboratory Agency (TVLA), Northern zone in Arusha for laboratory analysis, where methylene blue staining technique diagnosed $B$. anthracis, the causative agent of anthrax. Additional tissue samples of wild animals (6 wildebeest, 2 grant gazelle, and one rabbit) and five human blood samples (5 $\mathrm{ml}$ each) were taken into an EDTA vacutainers from suspected cases. All samples were transported at a refrigeration temperature to the TVLA in Arusha for further laboratory analysis using polymerase chain reaction (PCR) techniques. We used the QIAamp Mini DNA Kit (Qiagen, Germany) for the DNA extraction following manufacturer's instructions. Homogenized tissues were mixed with QIAGEN Protease (proteinase $\mathrm{K}$ ) and a lysis buffer proportionally, and the mixture was incubated at $56^{\circ} \mathrm{C}$ for 10 min. Afterward, proteins were precipitated by addition of $200 \mu 1$ ethanol to the sample mixture by pulse vortexing for $15 \mathrm{~s}$. The mixture was then centrifuged in the $1.5 \mathrm{ml}$ microcentrifuge tube to remove drops from inside the lid. The lysate was passed through a QIAamp Mini spin column and added $500 \mu \mathrm{l}$ buffer AW1 without wetting the rim and then centrifuged at $8000 \mathrm{rpm}$ for $1 \mathrm{~min}$. DNA was eluted using 50 $\mu 1$ of sterile water and stored at $-20^{\circ} \mathrm{C}$ until a realtime quantitative PCR (qPCR) for B. anthracis was performed. The detection of $B$. anthracis was done by aliquoting $122 \mu \mathrm{l}$ ( 24 reactions) of grade water in Eppendorf then Dynamo Color flash master mix, primer (R and $\mathrm{F}$ ), probe $10 \mu \mathrm{M}$, and grade water were added. After vortexing, the master mix for $10 \mathrm{~s}$ and in each well of the PCR plate, $22.5 \mu 1$ of the master mix, and $2.5 \mu 1$ of DNA template and control sample were added into a PCR plate. The mixture was put into the PIKO - real-time qPCR machine which was connected to a computer with an installed software and the results were read according to a quick guide of PCR analysis procedure version 4 of 2016 with a CQ value range of 25-35. From each sample, we ran against anthrax (B. anthracis) virulence plasmid Pag (pOX1) and Cap (pOX2) as described by Fasanella et al. [32]. Control-positive DNA used was obtained from the Finnish Defense Forces Center for Bio-threat Detection (MIL - Con).

\section{Data management and analyses}

A checklist was prepared to capture quantitative data of human, suspect cases, and the variables collected were: The location of the cases, age, sex, date of disease onset, signs and symptoms, specimen taken, date of specimen collection, type of drugs given (if the patient presented to a health facility), and the outcome of treatment (died or recovered). The qualitative information was obtained by observation during house-to-house visits and while conducting meetings with local officials. A map to indicate locations of the human cases was drawn on the Quantum GIS software (http://www.qgis.org/en/site/forusers/index.html). Data were entered in the Microsoft Excel Spreadsheet and analyzed by producing pivot tables and graphs. Furthermore, the databases were transferred to STATA (SE/14 for Windows, StataCorp, and College Station, TX) for additional statistical analyses [33].

\section{Findings dissemination strategy}

We disseminated the findings of the study to responsible officials in Selela ward, Monduli district in Arusha region and at the national level through reports, and meetings and recommendations were made for further control and prevention of the outbreak.

\section{Results}

Laboratory investigation confirmed anthrax through methylene blue staining and real-time qPCR techniques. Other samples did not amplify either with Pag (pXO1) nor did Cap (pXO2) that was run with control samples amplified with a standard curve CQ value average of 34.59. As mentioned earlier, livestock carcasses (10 cattle, 26 goats, and three sheep) were not available for sampling as they were reported to have either been consumed or hidden by owners. A total of 131 carcasses of wild animals were counted, the majority $(83 \%)$ being wildebeest. Other carcasses of wild animals (16\%) were for grant gazelle and $0.8 \%$

Table-1: Distribution of human cases and animal carcasses identified in Selela ward following anthrax outbreak, November 2016.

\begin{tabular}{llc}
\hline Species affected & $\begin{array}{l}\text { Human cases and } \\
\text { animal carcasses }\end{array}$ & \\
\hline Human cases, sex & Male & $11(52.38)$ \\
& Female & $10(47.62)$ \\
Human cases, age & $\leq 5$ & $9(42.85)$ \\
group & & \\
& $6-15$ & $7(33.33)$ \\
& $16-25$ & $3(14.28)$ \\
Livestock carcasses & $\geq 26$ & $2(9.54)$ \\
& Cattle & $10(25.64)$ \\
Wildlife carcasses & Goats & $26(66.67)$ \\
& Wildebeest & $3(7.69)$ \\
& Grant gazelle & $109(83.21)$ \\
& Rabbit & $21(16.03)$ \\
& & $1(0.76)$ \\
\hline
\end{tabular}

International Journal of One Health, EISSN: 2455-8931 
for the rabbit. Out of 21 human, suspected cases, the majority were under 5 years of age $(42.85 \%)$ followed by the age group of 6-15 years $(33.33 \%)$ as shown in Table-1.

Five villages were visited, these included Selela, Mbaash (Selela ward), Mungere (Mto wa $\mathrm{Mbu}$ ward), and Oltukai (Lake Manyara ward) for active searching of anthrax suspected cases and dissemination of health education on prevention and control of anthrax outbreak. We observed that the Maasai communities were still engaging themselves in activities which are posing a risk for anthrax transmission. All the livestock kept by the Maasai in Monduli district were not vaccinated against anthrax. The Maasai spend most of their time taking care of their animals, and the grazing environment makes their animals become in contact with wild animals. Due to their intimate contact with livestock and their products, the Maasai are predisposed to different zoonotic diseases including anthrax. The local people were observed dressing dead domestic and wild animals for consumption, and this was mostly done by women and children. The dried hides and skins from such animals were used as bedding materials, ropes or donkey luggage pockets and wildebeest tail brush as swats for chasing flies.

In the meetings conducted with local people, anthrax was reported as being brought by bad spirits of Maasai ancestors. When anthrax outbreak occurs, they tend to tie a small piece of animal skin on the finger as a way of chasing out the bad spirit from the household which is perceived to protect human from acquiring anthrax. It was further observed that anthrax outbreak in livestock, wildlife animals, and humans occurred at the same time with overlapping dates in November 2016 (Figure-1). It is an indication that the existing interactions between animals and humans in different ways pose risks for anthrax transmission across the species.

A total of two suspected cases of human anthrax were reported from livestock keeping households identified during community-based case searching, and all had skin lesions suggestive of cutaneous anthrax. All patients were treated at Mto wa Mbu health centre, Selela, Mungere, Mswakini, Oltukai, and Simangori dispensaries and recovered. On history taking at health facilities where they were attended, it was found that all of the human anthrax patients had a history of coming into direct contact with carcasses (touching or butchering) of dead animals whose causes of death was not established.

The human index case was reported on $5^{\text {th }}$ November 2016 (Figure-1) through the e-IDSR system, and this was preceded with the verbally reported deaths in livestock and wild animals in Selela Village. The 21 human anthrax suspected cases were mostly $(61.9 \%)$ from the villages of Selela ward. Other affected wards in different proportions were Eslalei (28.6\%), Lepurko (4.8\%), and Mswakini (4.8\%) (Figure-2). The incubation period of anthrax infection in humans is up to about 5-7 days depending on the microbial load. The number of cases started to decline after a national multi-sectoral team was deployed to the affected areas as it is illustrated in the epidemic curve of the human anthrax outbreak in Selela ward (Figure-3).

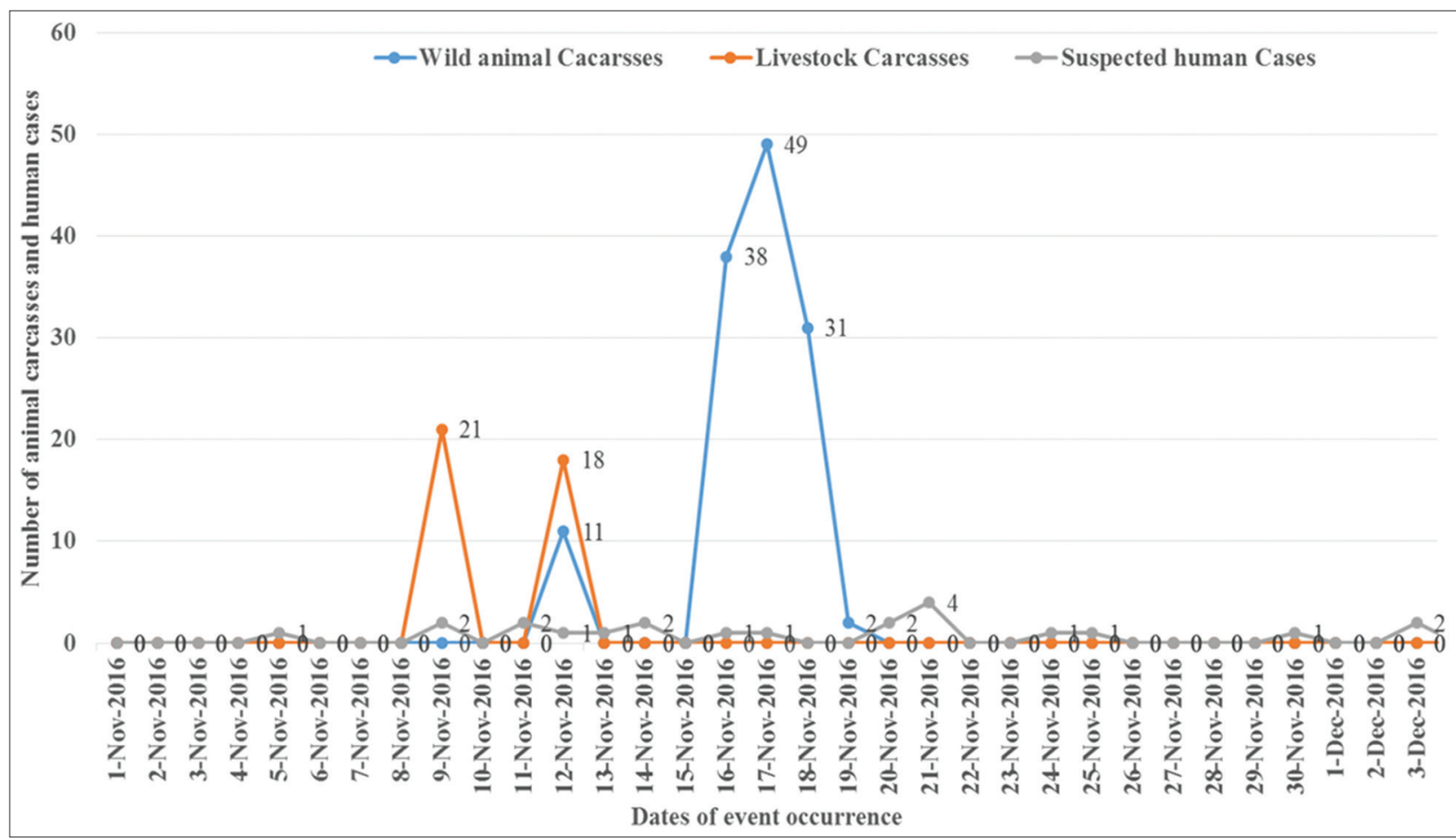

Figure-1: Trend of anthrax outbreak occurrences at the human, livestock, and wildlife interface in Selela ward in Monduli district, November 2016. 


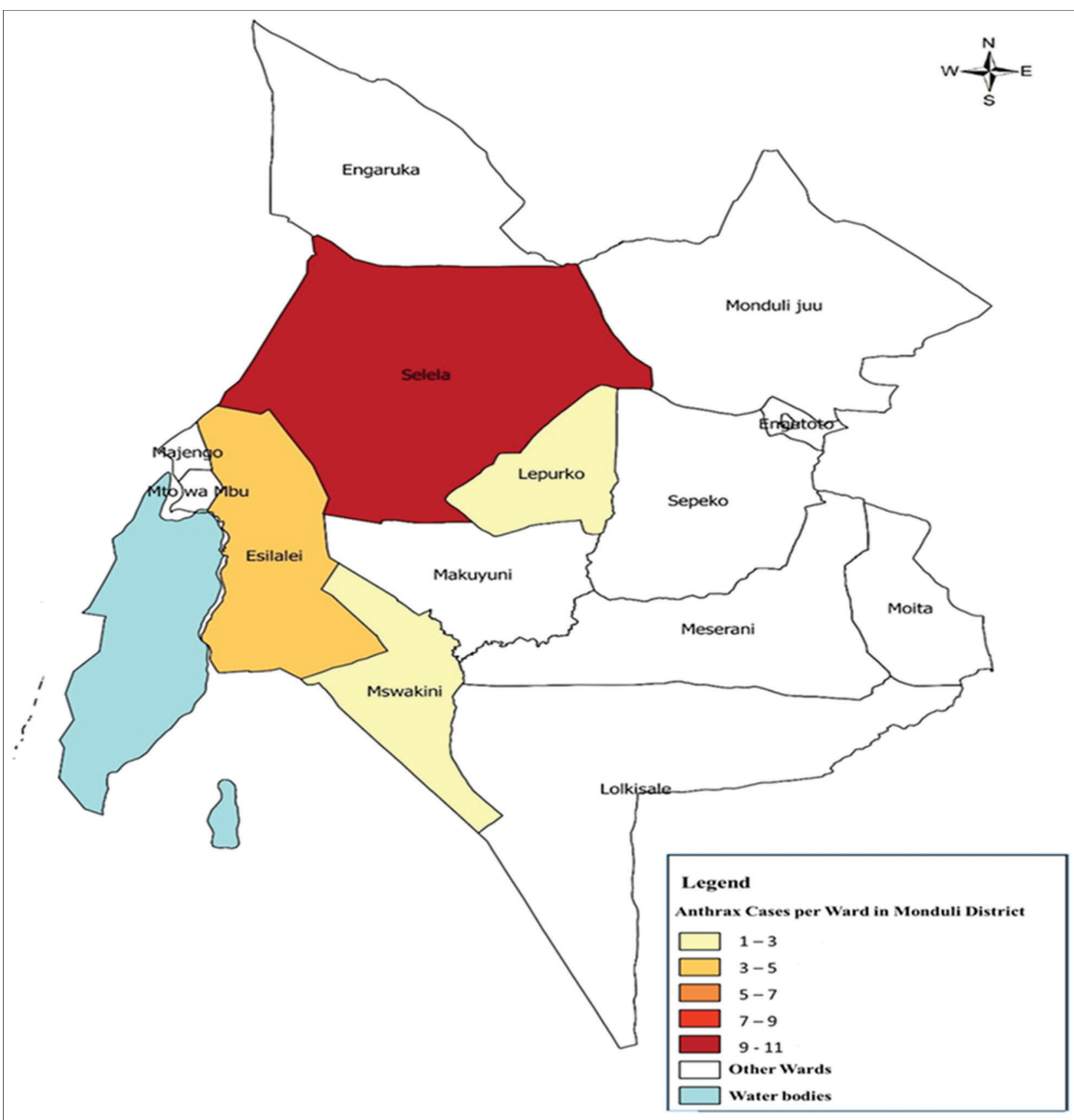

Figure-2: Map of Monduli district, showing the distribution of human anthrax cases in Selela ward, November 2016.

A total of eight affected households were visited, all were close to where wildebeest carcasses were found, and most of the members of the households admitted to having consumed meat from carcasses. The household herds reported grazing their livestock in proximity to places where some of the decomposing wildebeest were scattered on the ground. It was also reported that there were few livestock extension officers for providing extension and veterinary services to livestock and meat inspection. This led to livestock keepers treating their animals themselves. Livestock keepers requested to a response team to investigate on the suspected poisonous grass called endule in the Maasai language which is believed to cause livestock mortalities at the beginning of every rainy season.
The Laigwanan are the highly respected traditional leaders whose orders and directives are obeyed by the whole community within the locality. We educated and sensitized them on how to prevent transmission of anthrax and on early health-seeking behavior to a nearby health facility once any member of the family gets sick. They were also requested to ensure that sick and dead animals are immediately reported to the nearby livestock field officer and other authorities. The aim of using them was for easier dissemination of anthrax knowledge to the community because they are key people in the society. Finally, a local multi-sectoral group of experts and local leaders was formed in Selela ward to ensure early reporting of suspected anthrax cases and other epidemic-prone diseases in humans and animals. 


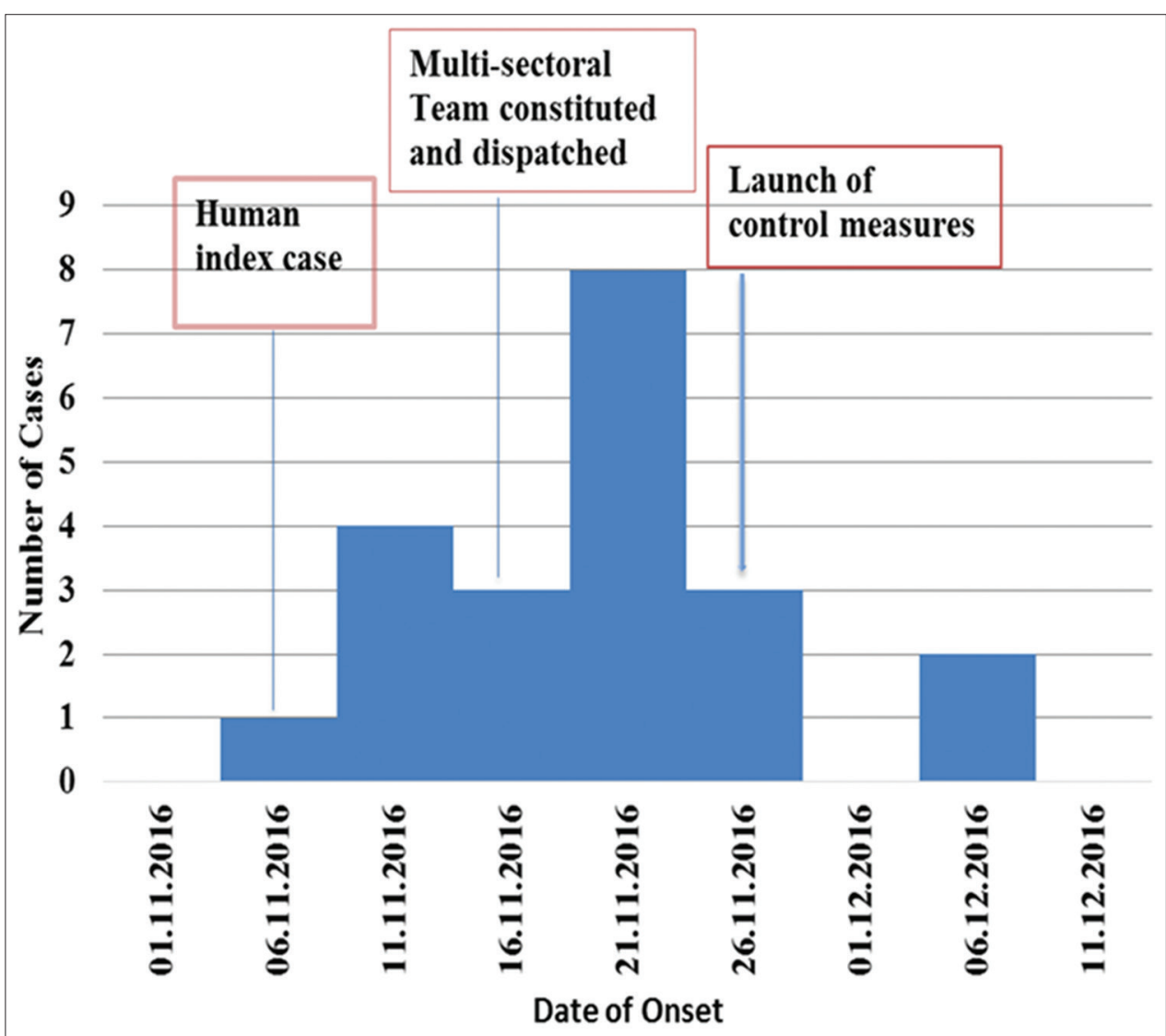

Figure-3: Epidemic Curve of human anthrax cases in Selela ward, Monduli district, November 2016.

The team consisted ofward livestock field officers, Clinical Officer, Community Development Officer, Ward Health Officer, Community Health Worker, Wildlife Officer, Agriculture Extension Officer, Village Chairperson, Village Executive Officer, Ward Executive Officer, and Councilors. The terms of reference were developed to describe the roles and responsibilities of each team member, and the official launching of the established team was proposed to be done in January 2017. A One Health Multi-sectoral Team was also developed at Arusha regional level comprising members from Monduli district (Human, livestock and wildlife Departments), TAWIRI, TANAPA, Tanzania Wildlife Authority, Nelson Mandela African Institute of Science and Technology, and Regional Secretariat (Veterinary Services, Human health, and Tourism Services). The developed team agreed to conduct joint meetings once per week and developed outbreak response action plan for the year 2016-2018.

\section{Discussion}

The findings on the carcasses such as body fluids including blood oozing from different natural orifices, excessive bloating, laboratory results of specimens taken from the carcasses, and the PCR assays confirmed that the animals died of anthrax. The skin lesions on human cases who attended health facilities after consuming carcasses also provided strong evidence to support the diagnosis of anthrax. The finding that human smear results were negative may be attributed to the effect of antibiotics taken after anthrax was suspected. Similar findings were observed in Chama district, Zambia, where the diagnosis of anthrax in human specimen was masked by antibiotic treatment initiated before blood sampling [34,35].

Clinical presentation in suspected humans coupled with a history of adequate exposure to infected animals and their products such as consumption of raw or undercooked meat and evidence of physical contact with infected carcasses are of great importance in initial diagnosis even before laboratory results. The advanced laboratory tests such as real-time PCR or serology (ELISA) serve as confirmatory tests, but most of the times, they are not readily available in typical field settings and also are not cost effective. The ideal laboratory test for anthrax should be sensitive, specific, and inexpensive [36]. Laboratory culture technique should be considered as a backup diagnostic procedure to support the conventional investigations, requiring standardized equipment, materials, and instructions at the levels of diagnosis [37].

As a control measure, burning of carcasses was the method of choice as scavengers had already opened most of the carcasses. This is because burying was, however, tedious, and costly as it required extensive workforce for excavating the burial pit of $6 \mathrm{ft}$ deep. Burning also destroyed and killed spores that contaminated bushes and served as a preventive measure for disease transmission to other grazing and browsing 
animals. In the current outbreak, wildebeests were the most affected wild animals, followed by grant gazelle and rabbit. All carcasses of wild animals, irrespective of the species, showed classical features of anthrax including exuding blood in natural body openings. As anthrax outbreak is dependent on the existence of susceptible hosts [38], intensified surveillance using a One Health approach, vaccination of livestock, proper disposal, and liming of the disposal sites of livestock and wild animal carcasses are the most efficient approaches for prevention and control of future occurrences of outbreaks. These may also serve as ways to reduce transmission of anthrax to humans [2].

It was evident that health-seeking behavior among members of the village with anthrax outbreak requires urgent attention. The eight households visited had cases with active skin lesions suggestive of being anthrax infection, but none of the cases had a history of attending to the nearby health facility for medical attention. Some cases vividly showed signs and history of using traditional ways including smearing cow dung on skin lesions. Eating carcasses were observed to be one of the common practices in Selela ward besides some of the on-going awareness campaigns and health education interventions. We suggested different intervention methods including the use of the influential local leaders known as Laigwanan and political leaders. Some pastoralists in the Maasai community mostly consider the extent of decomposition of a dead animal which they want to consume rather than potential risks of zoonotic disease transmission [23].

Livestock keepers in Selela ward requested for the investigation of the toxic grass called endule in Maasai language as they believed it was the cause of animal deaths every year. We collected samples of the reported toxic grasses to the NIMR laboratory for investigation but the results were not conclusive. To support toxicological investigation determination of seeds or plant materials in the rumen or stomach content or feces on autopsy and postmortem lesions are required to rule out plant poisoning [39].

The teams discovered several unreported deaths of wild animals during the survey. The local community associated the deaths to the fresh, lush pastures that follow long periods of drought season. It might be the basis for them to consume all the livestock carcasses in addition to some wild animals which died close to their bomas. Pastoralists might be aware of the risks associated with consumption of raw milk, blood, or raw or undercooked meat, but they still practice these risky behaviors particularly in rural areas [24]. The Maasai community has a belief that, drinking raw blood is important for young boys who have just been circumcised, as they believe that, raw blood replenishes nutrients lost during the procedure. On the other hand, lack of appropriate health education, poverty, or economic reasons can facilitate anthrax transmission as community members may tend to consume raw or undercooked meat, milk, or blood from animals infected with anthrax [40].

In Selela ward, it was evident that anthrax outbreak occurred at the human/livestock/wild animal's interface and this was facilitated by the existing interactions between them. Shortage of experts (livestock field officers and clinical officers) in this ward was reported which also contributes to late reporting of suspected human and animal cases, and hence, delayed response to the outbreaks. In most occasions, many anthrax outbreaks, especially from peripheral areas, are unlikely to have been properly diagnosed and reported timely to the district level leading to delayed outbreak response.

As opposed to the animal health sector where disease reporting at the village level is still a problem, the human/public health sector has the e-IDSR system, that allows a health facility to report cases of prioritized diseases to the higher levels of action. When the first case of human anthrax presented to the Mbaash dispensary in Selela ward with skin lesions suggestive of anthrax, headache, and fever, the facility clinician immediately fed the information onto the e-IDSR system using his mobile phone. It enabled all the higher levels including the Ministry of Health to get notified of the outbreak occurrence, so appropriate interventions were employed.

In Chama district, Zambia, the IDSR system reported two suspected cutaneous human anthrax cases, and the next day, a multi-sectoral response team was constituted and deployed to respond [41]. The animal health surveillance system in Monduli district is not well structured, with lack of veterinary extension officers to report or record deaths of livestock in the village and to the higher levels. It illustrates the challenges facing the veterinary sector and the need to address some of the issues for an effective One Health approach.

The previous analysis of anthrax epidemiological data in the world indicates the following estimated ratios: (i) 1 human cutaneous anthrax case to 10 anthrax livestock carcasses; (ii) 1 incidence of enteric human anthrax to 30-60 anthrax-infected animals eaten; and (iii) in humans, 100-200 cutaneous cases for each enteric case that occurs [42]. The clinical appearance of cutaneous anthrax is similar to a malignant pustule surrounded by edema at the infection site [43].

Selela ward has a National Park nearby and the surrounding bushy areas with free movement of wild animals. Studies have indicated that wild animals as being the reservoir of many human infectious diseases including anthrax [44]. It is estimated that more than third of new, emerging, or re-emerging human infectious diseases since an early $21^{\text {st }}$ century have been caused by pathogens originating from animals or products of animal origin [45]. Viruses, bacteria, and parasites have had their reservoirs in a host of animals such as those found in the wild, peri-domestic, and domestic [44]. 
The wide array of host species and the complex natural history of the pathogens concerned, pose big challenges for effective surveillance, prevention, and control of zoonotic diseases [1]. Several factors have been shown to facilitate the spillover of new diseases from livestock and wild animals into humans. These include environmental changes, population increase, microbiological adaptation to hosts and environment, and human practices and behavior [46]. Therefore, there is a need for various sector's collaboration during anthrax outbreak investigation and response including sharing the standards for livestock vaccination, meat inspection, and food hygiene in the country, East Africa Community (EAC) region and beyond.

Selela ward is a few kilometers from the border with Kenya, some livestock keepers cross the border to Kenya with their livestock, and there is also a free movement of wild animals across the Tanzania-Kenya border to Selela ward. The report of the EAC meeting is noted that Tanzania had developed country initiatives for cross-border diseases outbreak investigation and response. It was through sharing of information, surveillance data, laboratory confirmation and response initiatives in satellite laboratories, cross-border meetings, the establishment of cross-border diseases surveillance committees, and joint field simulations/ investigations between Burundi, Rwanda, Kenya, Uganda, and Tanzania [47]. This approach can, therefore, be expanded to involve livestock and wildlife sectors using One Health approach in the EAC region.

About $95 \%$ of the members of the community of Selela ward are livestock keepers, and 5\% are involved in crop production and business. The occurrence of anthrax in wild animals and the spillover to livestock and human is a wakeup call for a targeted: (i) Comprehensive multi-sectoral strategy involving routine vaccination of susceptible livestock (cattle, sheep, and goats) in anthrax hotspot areas using quality-assured and tested vaccines; (ii) enhanced surveillance system (with clear case definition) both in the public health and animal health sectors to ensure timely reporting and investigation of sudden death in livestock and wild animals; (iii) rapid disposal of dead livestock and wild animals, contaminated bedding materials and control of scavengers; (iv) extensive public awareness and compliance with general hygiene principles, including use of personal protective equipment by people who might be in contact with sickened or dead animals; (v) laws and regulation enforcement pertaining to anthrax control including quarantine of infected animals and animal products, and last but not least, enhanced communication and collaboration between countries to strengthen cross-border networks and strategies to curb zoonotic outbreaks.

Moreover, the next step for our project will be to map for a more detailed ecological niche modeling to better understand the epidemiologic knowledge of anthrax outbreaks. It will also assist to explore for a normalized difference vegetation index to get a better idea of how specific location might be associated with lives of grazing animals which are getting exposed to risks of disease transmission.

\section{Limitation}

The outbreak response did not test the statistical significance of the documented potential risk factors for anthrax transmission in Selela ward. Therefore, a qualitative anthropological study is recommended to measure the significance of the mentioned cultural-related practices that propagated disease transmission in the Maasai pastoralist communities living in the wildlife-livestock interface areas. The team did not find any livestock carcass, and hence, no sample was collected from livestock, it is possible that animals were consumed after they died. The intake of antibiotics before collection of blood samples from suspected cases compromised the confirmation of anthrax in humans.

The team had to use a translator to communicate with the Maasai as the majority of them did not speak Kiswahili which is the national language. Therefore, awareness of anthrax, health education, and other relevant outbreak information had to be translated to Maasai language. To some extent, this could not ascertain whether the right information was conveyed.

\section{Conclusion}

Anthrax outbreak was confirmed in wild animal samples taken from Selela ward, Monduli district, Arusha region in Northern Tanzania. The sudden death of animals with carcasses showing signs of anthrax was the first clear indication of the disease in animals. Clinical manifestation of cutaneous anthrax in human cases who consumed the meat from carcasses of dead domestic and wild animals during the outbreak cemented the diagnosis of an anthrax outbreak.

Although vaccination for livestock is considered to be among the most important interventional methods to prevent and control anthrax outbreaks in both humans and animals, no anthrax vaccination for livestock was observed during this outbreak response as in Tanzania vaccination is a private enterprise. Therefore, most livestock keepers do not consider it a cost-effective exercise, and hence, they either cannot afford to, or they opt not to vaccinate their animals. The authors would, therefore, recommend for anthrax vaccine to be a public good under a public-private partnership scheme. The study concludes that for an effective zoonotic diseases prevention and control, multi-sectoral coordination, communication, and collaboration using a One Health approach is paramount.

\section{Authors' Contributions}

ERM designed a study, conducted field survey, analyzed, interpreted data, and drafted the manuscript. JAA participated in the field survey; JSK participated in the field survey. EEM participated in the field survey. ZEM provided expertise on specimen 
laboratory analysis, HEN participated in designing a study and supervised drafting and writing of the manuscript; RHM participated in designing a study and supervised drafting and writing of the manuscript, and ES supervised the conception of the study, data analysis, interpretation, and drafting the manuscript. All authors revised and approved the final version of this manuscript.

\section{Acknowledgments}

The authors wish to thank all parties that supported this response, and specific thanks should go to the Prime Minister's Office for coordinating the work, Ministry of Health Community Development, Gender, Elderly and Children, Ministry of Agriculture, Livestock and Fisheries, Ministry of Natural Resources and Tourism, particularly TAWIRI, Chief Park Warden for Manyara National Park, NCAA, TANAPA, Arusha Regional Authorities, Monduli District Authorities and Selela Ward Authorities, for their valuable contribution during response to this outbreak. The authors are indebted to the following experts whom without their valuable contribution this activity would not be completed, Dr. Frida Mokiti (Arusha Regional Medical Officer), Ms. Vones Uiso (Arusha Regional Health Officer), Dr. Titus Mmasi (Clinician at Monduli District Hospital), Mr. Ferdinand Matata (Laboratory Epidemiologist at Monduli District Hospital), Dr Augustino Marmo (Veterinary Officer at Monduli District Council), and Honorable Cathberth Meena (Councilor of Selela Ward). Last but not least, we would like to thank the USAID through the Preparedness and Response (P \&R) project (Grant No: AID - OAA - A - 14 - 00098, and Project No: Emerging Pandemic Threats -2 phase [EPT -2] project) for their financial support.

\section{Competing Interests}

The authors declare that there were no competing interests.

\section{References}

1. World Health Organization. Anthrax in Humans and Animals. Geneva, Switzerland: World Health Organization; 2008.

2. Shandomy AE, Raizman E, Bruni M, Palamara E, Pittiglio C, Lubroth J. Anthrax outbreaks: A Warning for Improved Prevention, Control and Heightened Awareness. Page No. 37. 2016. Available from: http://www.empres-animalhealth@fao.org; http://www.fao.org/ag/empreshtml. Accessed on 12-01-2017.

3. Bengis RG, Frean J. Anthrax as an example of the one health concept. Rev Sci Tech 2014;33:593-604.

4. Sirisanthana T, Brown AE. Anthrax of the gastrointestinal tract. Emerg Infect Dis 2002;8:649-51.

5. Lembo T, Hampson K, Auty H, Beesley CA, Bessell P, Packer C, et al. Serologic surveillance of anthrax in the Serengeti ecosystem, Tanzania, 1996-2009. Emerg Infect Dis 2011;17:387-94.

6. Blackburn JK, Curtis A, Hadfield TL, O'Shea B, Mitchell MA, Hugh-Jones ME. Confirmation of Bacillus anthracis from flesh-eating flies collected during a West Texas anthrax season. J Wildl Dis 2010;46:918-22.
7. Fasanella A, Scasciamacchia S, Garofolo G, Giangaspero A, Tarsitano E, Adone R. Evaluation of the house fly Musca domestica as a mechanical vector for an anthrax. PLoS One 2010;5:e12219.

8. Manchee RJ, Broster MG, Melling J, Henstridge RM, Stagg AJ. Bacillus anthracis on Gruinard Island. Nature 1981;294:254-5.

9. Fasanella A, Adone R, Hugh-Jones M. Classification and management of animal anthrax outbreaks based on the source of infection. Ann Ist Super Sanita 2014;50:192-5.

10. Anthrax Outbreak in a Swedish Beef Cattle Herd - 1st Case in 27 Years: Case Report; 2010. Available from: http://www. actavetscand.com/content/52/1/7. Accessed on 12-02-2017.

11. Chen WJ, Lai SJ, Yang Y, Liu K. Mapping the distribution of anthrax in mainland China, 2005-2013. PLoS Negl Trop Dis 2016;10:e004637.

12. Fasanella A, Garofolo G, Galante D, Quaranta V, Palazzo L, Lista F, et al. Severe anthrax outbreaks in Italy in 2004: considerations on factors involved in the spread of infection. New Microbiol 2010;33:83-6.

13. Garofolo G, Serrecchia L, Corrò M, Fasanella A. Anthrax phylogenetic structure in Northern Italy. BMC Res Notes 2011;4:273.

14. Chakraborty A, Khan SU, Hasnat MA, Parveen S, Islam MS, Mikolon A, et al. Anthrax outbreaks in Bangladesh, 20092010. Am J Trop Med Hyg 2012;86:703-10.

15. Mondal SP, Yamage M. A retrospective study on the epidemiology of anthrax, foot and mouth disease, haemorrhagic septicaemia, peste des petits ruminants and rabies in Bangladesh, 2010-2012. PLoS One 2014;9:e104435.

16. Chikerema SM, Pfukenyi DM, Matope G, Bhebhe E. Temporal and spatial distribution of cattle anthrax outbreaks in Zimbabwe between 1967 and 2006. Trop Anim Health Prod 2012;44:63-70.

17. Munang'andu HM, Banda F, Chikampa W, Mutoloki S, Syakalima M, Munyeme M. Risk analysis of an anthrax outbreak in cattle and humans of Sesheke district of Western Zambia. Acta Trop 2012;124:162-5.

18. Wafula MM, Patrick A, Charles T. Managing the 20042005 anthrax outbreak in Queen Elizabeth and Lake Mburo national park. Afr J Ecol 2008;46:24-31.

19. Hampson K, Lembo T, Bessell P, Auty H, Packer C, Halliday J, et al. Predictability of anthrax infection in the Serengeti, Tanzania. J Appl Ecol 2011;48:1333-44.

20. Tesha H. Anthrax Hits Rombo Killing One; 2016. Available from: http://www.the citizencotz/News//1840340/310016/-indexhtml. Accessed on 06-01-2017.

21. Zhang HL, Mnzava KW, Mitchell ST, Melubo ML. Mixed methods survey of zoonotic disease awareness and practice among animal and human healthcare providers in Moshi, Tanzania. PLoS Negl Trop Dis 2016;10:e004476.

22. Cleaveland S, Sharp J, Abela-Ridder B, Allan KJ, Buza J, Crump JA, et al. One health contributions towards more effective and equitable approaches to health in low-and middle-income countries. Philos Trans R Soc Lond B Biol Sci 2017;372. pii: 20160168.

23. Mangesho PE, Neselle MO, Karimuribo ED. Exploring local knowledge and perceptions on zoonoses among pastoralists in northern and eastern Tanzania. PLoS Negl Trop Dis 2017;11:e005345.

24. Swai ES, Schoonman L, Daborn CJ. Knowledge and attitude towards zoonoses among animal health workers and livestock keepers in Arusha and Tanga, Tanzania. Tanzan J Health Res 2010;12:280-6.

25. Grace D, Lindahl J, Wanyoike F, Bett B, Randolph T. Poor livestock keepers: ecosystem-poverty-health interactions. Philos Trans R Soc Lond B Biol Sci 2017;372. pii: 20160166.

26. The United Republic of Tanzania U. Prime Minister's Office, One Health Strategic Plan 2015-2020.

27. Tanzania, Ofisi ya Taifa ya T. 2012 Population and Housing Census: Key findings. Dar es Salaam: National Bureau of Statistics; 2014. 
28. The United Republic of Tanzania U. The National Integrated Diseases Surveillance and Response (IDSR) Guidelines. $2^{\text {nd }}$ ed. 2011. Available from: http://wwwmohgotz. Accessed on 15-06-2017.

29. Alcia A. Williams, Umesh D. Parashar, Adrian Stoica, Renee Ridzon, David L. Kirsche, Richard F. Mayer. . Bioterrorism related anthrax surveillance; 2012. http://wwwcdcgov/nci$\mathrm{dod} / \mathrm{EID} /$ vol8no10/02-0399htm. 2010; 8(10).

30. Awoonor-Williams J, Apanga P, Anyawie M, Abachie T, Boidoitsiah S, Opare J, et al. Anthrax outbreak investigation among humans and animals in Northern Ghana: Case report. Int J Trop Dis Health 2016;12:1-11.

31. Turnbull PC. World Health Organization, Department of Communicable Disease Surveillance, Response. Guidelines for the Surveillance and Control of Anthrax in Humans and Animals. Geneva, Switzerland; 1998.

32. Fasanella A, Galante D, Garofolo G, Jones MH. Anthrax undervalued zoonosis. Vet Microbiol 2010;140:318-31.

33. StataCorp. Stata: Release 14. Statistical Software. College Station, TX: StataCorp LP. Lakeway Drive: Stata Press Publication; 2015. p. 4905.

34. Matero P, Hemmilä H, Tomaso $H$, Piiparinen $H$, Rantakokko-Jalava K, Nuotio L, et al. Rapid field detection assays for Bacillus anthracis, Brucella spp., Francisella tularensis and Yersinia pestis. CMI Clin Microbiol Infect 2011;17:34-43.

35. Hang'ombe MB, Mwansa JC, Muwowo S, Mulenga P, Kapina M, Musenga E, et al. Human-animal anthrax outbreak in the Luangwa valley of Zambia. Trop Doct 2012;42:136-9.

36. World Health Organization. Anthrax: Memorandum from WHO Meeting of a Working Group on Anthrax; 1995.

37. World Health Organization. Working Group Meeting on Anthrax Control and Research with Special Reference to
National Develpment in Africa; 1992.

38. Hugh-Jones ME, de Vos, V. Anthrax and Wildlife. Rev Sci Tech Off Int Epiz 2002;21:359-83.

39. Bailey EM. Physiologic response of livestocks to Toxic plants. J Range Manag 1978;31:343-7.

40. Sitali DC, Mumba C, Skjerve E, Mweemba O, Kabonesa C, Mwinyi MO, et al. Awareness and attitudes towards anthrax and meat consumption practices among affected communities in Zambia: A mixed methods approach. PLoS Negl Trop Dis 2017;11:e0005580.

41. Kasolo F, Yoti Z, Bakyaita N, Gaturuku P, Katz R, Fischer JE, et al. IDSR as a platform for implementing IHR in African countries. Biosecur Bioterror 2013;11:163-9.

42. Turnbull. Guidelines for the Surveillance and Control of Anthrax in Humans and Animals. $3^{\text {rd }}$ ed. World Health Organization; 1998.

43. Jarap. Two cases of human cutaneous anthrax in Bosnia and Herzegovina. Rapid Communications; 2014. Available from: http://www.eorosurveillance.org. Accessed on 06-04-2017.

44. Rusch G.M, Stokke S, Roskaft E, Mwakalebe G, Wiik H, Arnemo J, Lyamuya R. Human - Wildlife interactions Western Serengeti in Tanzania; Nina Report; 2005.

45. Coker R, Rushton J, Mounier-Jack S, Karimuribo E, Lutumba P, Kambarage D, et al. Towards a conceptual framework to support one-health research for policy on emerging zoonoses. Lancet Infect Dis 2011;11:326-31.

46. World Health Organization. The Control of Neglected Zoonotic Diseases. From Advocacy to Action; 2014. Available from: http://wwwwhoint. Accessed on 14-05-2017.

47. Report. Joint Cross Border Technical Meeting between the United Republic of Tanzania and the Republic of Kenya, Kajiado County - Kenya; 2014. 